\title{
The use of accounting information for assessing the economic security of commercial banks
}

\author{
Anastasia Gontar ${ }^{1}$, Vladimir Plotnikov ${ }^{2,3,},{ }^{,}$Nadezda Chernovanova $^{4}$, and Elena Yagupova ${ }^{4}$ \\ ${ }^{1}$ Volgograd State Technical University, 2 Degtyareva str., Volgograd, Russia, 400006 \\ ${ }^{2}$ Saint-Petersburg State University of Economics, 21 Sadovaya str., St. Petersburg, Russia, 191023 \\ ${ }^{3}$ South West State University, 9450 let Oktiabria str., Kursk, Russia, 305040 \\ ${ }^{4}$ Volgograd State Agricultural University, 26 Universitetsky av., Volgograd, Russia, 400002
}

\begin{abstract}
The authors studied the use of accounting information for assessing the level of economic security of commercial banks. The article substantiates the choice of financial indicators of credit institutions as input parameters of the neural network. The analytical platform Deductor Studio Academic was chosen as the instrumental environment for assessing the level of economic security of banks. With its help, cluster analysis was performed. The division of the initial set of credit institutions into subsets (economic security classes) used the k-means method with splitting into three clusters: cluster 0 - "Optimal level of economic security", cluster 1 "Conditionally optimal level of economic security", cluster 2 - "Low level of economic security". The proposed data model with the results of the division of credit institutions into clusters according to the financial indicators of International Financial Reporting Standards made it possible to draw conclusions about the level of economic security of credit institutions and justify the choice of accounting information indicators for implementing a neural network approach to banking research.
\end{abstract}

\section{Introduction}

Modern economic development essentially depends on the availability and sufficiency of such a factor of production as capital. The economic availability of capital is especially significant for the development of cities where the "density" of economic activity is the highest. Therefore, it is necessary to have a developed and stable banking system. It acts as a factor in the successful development of the economy in general and the urban economy in particular [1].

In modern conditions of economic transformation, changes in the system of global competition, the sustainability and predictability of the development of economic systems at micro, meso, macro, and mega levels objectively decreases [2]. This also applies to the activities of commercial banks. An important and urgent problem is ensuring the economic security of the banking system. In today's situation, there is not a single issue of economic

\footnotetext{
*Corresponding author: plotnikov_2000@mail.ru
} 
development that does not directly or indirectly depend on the stability of the banking system.

Analysis of approaches to ensuring the economic security of commercial organizations (in particular, banks) allowed us to conclude that an effective system of economic security is based on the use of accounting information. It needs an adequate analysis and evaluation. This speeds up the process of making informed management decisions, contributes to sustainable development [3].

Accounting is an integrating component of analytical information about an economic entity. Accounting documents, summarizes, classifies objective information about the activities of commercial banks. Control of the financial activities of a credit institution allows you to take measures to prevent threats to economic security. Accounting information for assessing the level of economic security can be used by investors, lenders, shareholders, customers, regulatory bodies, etc., which contributes to improving the financial stability of the banking system [4].

The purpose of this study is to develop scientific and methodological tools for using accounting information to assess the level of economic security of commercial banks. The study was conducted on the materials of commercial banks of the Russian Federation.

\section{Materials and Methods}

The assessment of the stability and economic security of the bank is based on a system of indicators (criteria). In the literature and in practice, various systems of similar indicators are used. As a rule, the main ones are financial indicators [5, 6].

The regulatory legal act in the Russian Federation, which defines the main groups of financial stability indicators of a bank, is Bank of Russia Ordinance No. 3277-U dated $06 / 11 / 2014$ "On methods for assessing the financial stability of a bank in order to recognize it sufficient to participate in the deposit insurance system". The indicators of financial stability of the bank in this document include: financial results, capital, loan portfolio growth, etc.

As part of the study, a methodology was proposed for assessing the level of economic security of commercial banks based on the neural network approach $[7,8]$. In accordance with the order of the Ministry of Finance of the Russian Federation dated 25/11/2011 No. 160n, the accounting reports of business entities are prepared in accordance with the requirements of International Financial Reporting Standards (IFRS). Therefore, as input parameters of the $F_{E S}$ economic security function, financial performance of banks under IFRS was used (he unit of measure is annual interest):

- Relative financial results for the reporting period $\left(x_{1}\right)$.

- Change in the value of the loan portfolio $\left(x_{2}\right)$.

- Capital growth $\left(x_{3}\right)$.

- The volume of attracted funds from individuals $\left(x_{4}\right)$.

The calculation formula is:

$$
F_{E S}=\frac{A e^{2 B \cdot \frac{x_{1} \cdot x_{2} \cdot x_{3} \cdot x_{4}}{x_{1}+x_{2}+x_{3}+x_{4}}}-1}{A e^{2 B \cdot \frac{x_{1} \cdot x_{2} \cdot x_{3} \cdot x_{4}}{x_{1}+x_{2}+x_{3}+x_{4}}}+1},
$$

where $A$ and $B$ are constant coefficients.

The solution of the problem of assessing the economic security of banks was implemented using the Deductor Studio Academic toolkit. Using this software allows you to automate a number of analytical tasks, the solution of which contributes to the adoption 
of optimal management decisions. As a result, it is possible not only to evaluate, but also to increase the level of economic security of the banks studied.

We used the neural network approach to assess the level of economic security of commercial banks $[9,10]$. The financial data of Russian banks according to IFRS were considered as initial data. The analysis of financial indicators was carried out for 92 credit institutions included in IFRS statements for the last two years. The information provided on the official website of the Central Bank of the Russian Federation (see: http://www.cbr.ru) was used as the initial data.

\section{Results and Discussion}

To build a simulation model in the form of a neural network, the "Neural network" node of the Deductor platform was used. When training the neural network, the selected financial indicators of commercial banks were used as input parameters, and the output parameters were the values of the FES economic security function (Table 1). The constructed neural network allows analyzing the impact of individual financial indicators on the level of economic security of a particular credit institution.

Table 1. Financial indicators of the bank's activities, and also the estimated values of the economic security function, fragment (The authors' calculations based on the source data of the Bank of Russia).

\begin{tabular}{|l|c|c|c|c|c|}
\hline \multirow{2}{*}{\multicolumn{1}{|c|}{ Bank }} & \multicolumn{4}{c|}{ Neural Network Input Parameters } & Output \\
\cline { 2 - 6 } & $x_{1}$ & $x_{2}$ & $x_{3}$ & $x_{4}$ & $F_{E S}$ \\
\hline Vostochny PJSC & -129.91 & -14.61 & 65.63 & -17.05 & 1.00 \\
\hline Binbank PJSC & -114.49 & 84.81 & 431.17 & 236.77 & -1.00 \\
\hline Rosselkhozbank JSC & -37.47 & -0.47 & $-15,93$ & 26,00 & 0,09 \\
\hline UniCreditBank JSC & $-9,68$ & $-21,94$ & 10,46 & $-5,08$ & 0,15 \\
\hline Citybank JSC & -18.62 & -18.27 & -0.16 & -24.98 & -0.01 \\
\hline Rosbank PJSC & -133.33 & -7.36 & 2.57 & 4.49 & -0.03 \\
\hline Vozrozhdenie PJSC & -155.26 & 11.17 & 7.21 & 8.25 & 0.27 \\
\hline Promsvyazbank PJSC & -112.80 & -2.06 & 9.71 & 38.49 & -0.43 \\
\hline Absolut Bank PJSC & -38.78 & 10.43 & 11.52 & 59.48 & -0.98 \\
\hline Raiffeisenbank JSC & -6.43 & -9.17 & 22.39 & -3.59 & -0.48 \\
\hline Sberbank PJSC & 143.11 & -7.30 & 18.80 & 3.37 & -0.15 \\
\hline VTB 24 PJSC & 1355.88 & 14.33 & 28.93 & 7.66 & 0.79 \\
\hline Moscow Credit Bank PJSC & 626.67 & 5.63 & 12.03 & 23.79 & 0.48 \\
\hline
\end{tabular}

The generated model consists of five input signals, two neurons of the hidden layer (their function is the processing of input signals) and one output neuron responsible for the formation of network activity (Fig. 1).

Analytical platform Deductor is an effective software tool that allows you to perform cluster analysis. For splitting the initial set of credit institutions into subsets (economic security classes), the k-means method was chosen with splitting into three clusters:

- Cluster 0 - "The optimal level of economic security".

- Cluster 1 - "Conditionally optimal level of economic security".

- Cluster 2 - "Low level of economic security".

Figure 2 shows the clustering results window - cluster profiles with achieved solution accuracy. The calculations showed that the overwhelming majority of credit institutions $(82.6 \%+14.1 \%=96.7 \%)$ are in clusters with the "optimal level of economic security" and "conditionally optimal level of economic security", which indicates the stability of the national banking system Russian Federation. Only 3.3\% of commercial banks have a low level of economic security. 


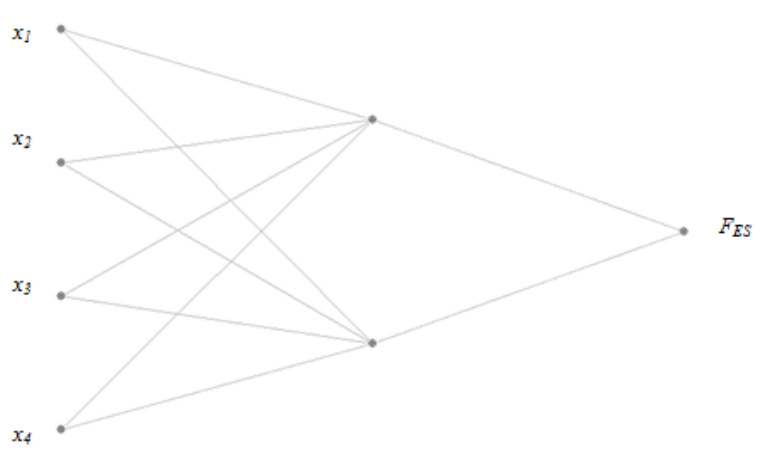

Fig. 1. Structure of neural network.

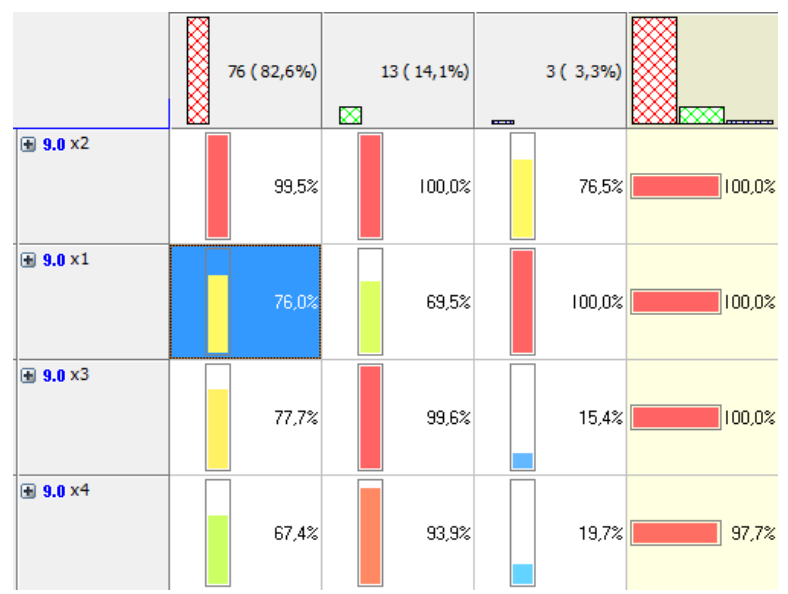

Fig. 2. The result of clustering commercial banks in terms of economic security.

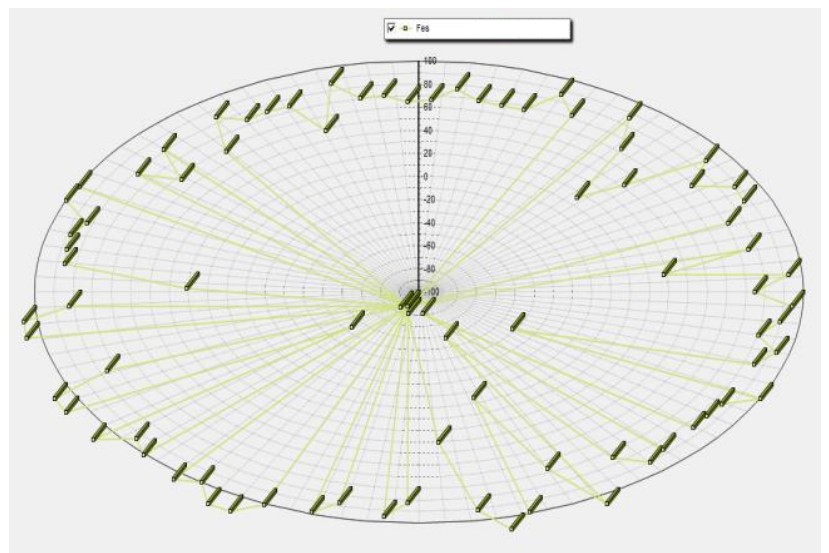

Fig. 3. The value chart of the economic security function (normalized data).

An addition to the solution of the task is to visualize the results of clustering using a normalized diagram of the values of the economic security function (Fig. 3). In this case, the fact that most credit institutions have a sufficient level of economic security is clearly 
presented. This demonstrates the effectiveness of the management of Russian banks and the state regulation of their activities.

\section{Conclusion}

As a result of the study, the following steps were implemented:

- Based on open statistical reporting, a set of indicators was formed reflecting the financial activities of 92 Russian commercial banks.

- Using the neural network modeling method, the values of the economic security function for each commercial bank presented in the sample were calculated.

- Using the Neural Network node of the analytical platform Deductor a neural network was built. This network allows you to analyze the impact of individual indicators on the level of economic security.

- Data clustering was carried out, which resulted in the identification of clusters with different levels of economic security (cluster 0 - "Optimal economic security level", cluster 1 - "Conditionally optimal economic security level", cluster 2 - "Low economic security level").

- A normalized chart of values of the function of economic security of banks was constructed. This allowed to visualize the results of scientific research.

The proposed methodology was tested by conducting economic modeling. Its adequacy has been proven. The methodology can be applied by the bank management during the assessment of the level of economic security. The splitting into clusters according to IFRS financial indicators made it possible to draw objective conclusions about the level of economic security of credit institutions and justify the choice of accounting information for the implementation of the neural network approach. Cluster analysis also makes it possible to identify unstable elements of the banking system and take appropriate measures to prevent threats and reduce risks. The methodology developed by the authors can be applied to analyze the performance of various economic entities, not just commercial banks.

\section{References}

1. U.G. Benna, Industrial and Urban Growth Policies at the Sub-National, National, and Global Levels (IGI Global, Hershey, PA, 2019)

2. Y. Vertakova, V. Plotnikov, Economic Annals-XXI 156(1-2), 37-40 (2016) doi: 10.21003/ea.V156-0008

3. N.N. Balashova, V.A. Melikhov, M.A. Ovchinnikov, E.M. Egorova, E.V. Tokareva, European Research Studies Journal 19(2), 153-160 (2016)

4. A.A. Gontar, Advances in Economics, Business and Management Research 39, 737740 (2018)

5. S.M. Glover, D.F. Prawitt, W.F. Messier, Auditing \& Assurance Services: A systematic approach (McGraw-Hill, 2014)

6. G.V. Fedotova, N.I. Lomakin, D.D. Tkachenko, A.A. Gontar, The Future of the Global Financial System: Downfall or Harmony (Springer Nature, Switzerland, 2019)

7. L.O. Chua, L. Yang, IEEE Trans. on Circuits and Systems 35 (10), 1257-1272 (1988)

8. S. Bodrunov, V. Plotnikov, Y. Vertakova, IBIMA 2017 - Vision 2020: Sustainable Economic de., In. Management, and Global Growth 2017 1, 2666-2674 (2017)

9. A.A. Ermakova, Integration and Clustering for Sustainable Economic Growth (Springer International Publishing AG, Berlin, 2017) 